\title{
Acoustically induced shear stresses in the vicinity of microbubbles in tissue
}

\author{
Lewin, Peter A.; Jensen, Leif Bjørnø
}

Published in:

Acoustical Society of America. Journal

Link to article, DOI:

$10.1121 / 1.387549$

Publication date:

1982

Document Version

Publisher's PDF, also known as Version of record

Link back to DTU Orbit

Citation (APA):

Lewin, P. A., \& Jensen, L. B. (1982). Acoustically induced shear stresses in the vicinity of microbubbles in tissue. Acoustical Society of America. Journal, 71(3), 728-734. https://doi.org/10.1121/1.387549

\section{General rights}

Copyright and moral rights for the publications made accessible in the public portal are retained by the authors and/or other copyright owners and it is a condition of accessing publications that users recognise and abide by the legal requirements associated with these rights.

- Users may download and print one copy of any publication from the public portal for the purpose of private study or research.

- You may not further distribute the material or use it for any profit-making activity or commercial gain

- You may freely distribute the URL identifying the publication in the public portal

If you believe that this document breaches copyright please contact us providing details, and we will remove access to the work immediately and investigate your claim 


\title{
Acoustically induced shear stresses in the vicinity of microbubbles in tissue
}

\author{
Peter A. Lewin and Leif Bjørnø \\ Technical University of Denmark, DK-2800 Lyngby. Denmark \\ (Received 7 April 1981; accepted for publication 8 October 1981)

\begin{abstract}
The shear stresses in the vicinity of gaseous microbubbles in tissue irradiated by continuous and transient ultrasonic fields typical of those used in diagnostic practice have been calculated from a solution of the equation of motion of the bubble. The assumptions and limitations of the model have been considered, and within these limits, it appears that the steady stresses produced may lie above reported thresholds for biological effects. It would appear from the data in the literature that not all the biological effects reported
\end{abstract} \\ may be caused by stresses resulting from acoustic streaming.
}

PACS numbers: 43.80.Gx, 87.50.Ce, 43.25.Yw

\section{INTRODUCTION}

In an earlier work, ${ }^{1}$ it has been pointed out that, if gaseous microbubbles exist in biological tissue, their response to ultrasonic irradiation may be growth to a resonant size and the generation of both oscillatory and time independent flow (microstreaming) in their vicinity. This flow leads to local increases in shear stresses which may, by injuring the membranes, destroy cellular function. The present work represents the calculation of the potential influence of both steady state and oscillatory stresses.

Rooney ${ }^{2}$ has discussed similar phenomena at a frequency of the order of $20 \mathrm{kHz}$, but the present paper is particularly concerned with potential effects at the megahertz region of frequencies used in medical diagnosis and therapy.

In this paper emphasis has been put on the shear stresses associated with microstreaming, which are evaluated by the following procedure: The displacement amplitude of the bubble wall in environments represented by the cellular liquid structure of biological tis sue is determined from a numerical solution of the nonlinear equation of bubble motion. Then, with a knowledge of the amplitude, the streaming velocity $U$ and the velocity gradient $G$ are calculated on the basis of acoustic streaming theory. ${ }^{3}$ Finally, the hydrody namic, time-independent stresses affecting cell membranes can be obtained from the product of the shear viscosity coefficient $\eta_{l}$ of the liquid, and the velocity gradient $G$.

\section{THE GAS-BUBBLE MODEL}

The basic equation of bubble motion for the calculation of the amplitude of displacement of the bubble wall was derived by Lord Rayleigh in 1917, ${ }^{4}$ and has since been developed extensively ${ }^{5-10}$ to include such effects as liquid viscosity, surface tension, and losses due to thermal conductivity and sound radiation. In the calculations reported here it is assumed (Fig. 1) that the bubble is surrounded by an infinitely extended incompressible liquid of density $\rho_{l}$, surface tension $\sigma$, and viscosity $\eta_{l}$. The factors that enter the equation, i.e., bubble shape, damping mechanisms, poly tropic exponent of the gas in the bubble, and the liquid viscosity will each be discussed briefly in the following sections. The effect of the viscosity of the gas within the bubble was neglected.

\section{A. Shape of the bubble}

In medical ultrasonics the frequencies employed are usually confined to the range from 1 to $10 \mathrm{MHz}$ and therefore the ultrasonic wavelength $\lambda_{A}$ is much greater than the bubble radius at rest $R_{0} \simeq 1-3.5 \mu \mathrm{m} .{ }^{1}$ Consequently, the pressure acting on the bubble will be isotropic and radial mode pulsation will be assumed to dominate. Since the zeroth mode is the most important from energy considerations, ${ }^{11}$ it is assumed in subsequent discussions that the bubble maintains its spherical shape and that the bubble pulsations are of the zeroth mode. Even for nonspherical bubbles Strasberg ${ }^{11}$ has shown that the zeroth mode resonance frequency is practically independent of the bubble shape. A comprehensive description of the dynamics of nonspherical bubbles has been given by Hsieh. ${ }^{12}$

\section{B. Damping mechanisms}

It can be $\operatorname{shown}^{10,13}$ that for the case considered in which $R_{0} \simeq 1-3.5 \mu \mathrm{m},{ }^{1}$ viscous losses prevail. Con-

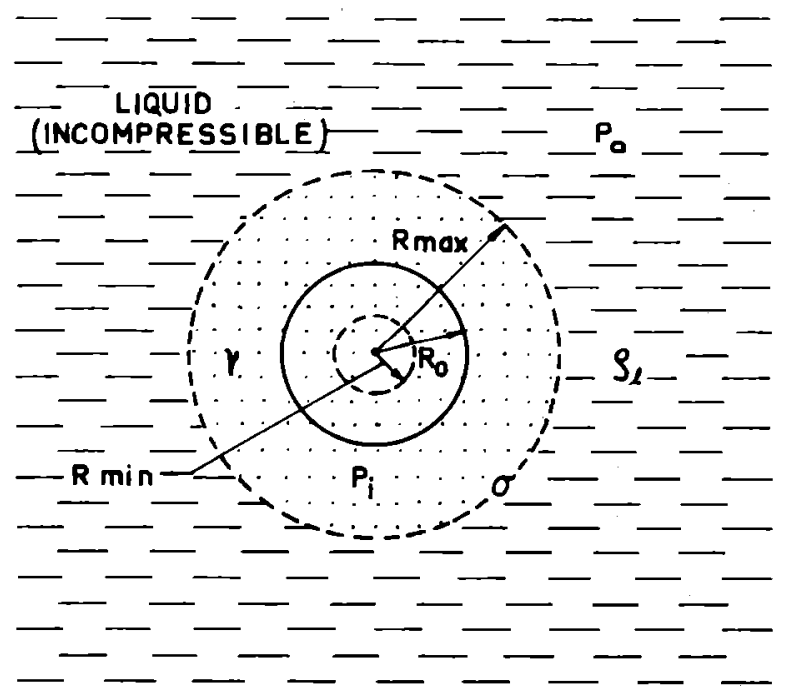

FIG. 1. The gas bubble model (see Ref. 9). 
sequently, in the present calculations the effects of damping due to sound radiation and thermal conductivity are neglected. However, if it is necessary, these effects can readily be introduced, as shown by Prosperetti," through an "effective viscosity," which includes losses due to thermal and viscous dissipation and radiation.

\section{Polytropic exponent $y$ of the gas in the bubble}

Details of the composition of the gas contained within the bubble are not known, but it probably consists of a mixture of $\mathrm{N}_{2}, \mathrm{O}_{2}, \mathrm{CO}_{2}$, and water vapor. The compression process of the gas in the bubble can the refore be described by a polytropic gas law. The polytropic exponent $\gamma$ was chosen on the basis of the results re ported by Chapman and Plesset. ${ }^{14}$ For the case of a mixture of $\mathrm{CO}_{2}$ and $\mathrm{H}_{2} \mathrm{O}$ vapor the polytropic exponent varies between $\gamma=1$ and $\gamma=1.33$. Since the bubble radii considered $\left(R_{0} \simeq 1-3.5 \mu \mathrm{m}\right)$ correspond to $\gamma$ $\simeq 1.03,{ }^{1}$ this value of the polytropic exponent is used in the calculations.

\section{Viscosity of the liquid}

The biological medium in which the potential influence of acoustically induced shear stresses is of greatest interest is that of mammalian tissue. However, as far as the present authors are aware there is no literature data available on the viscoelastic constants of the tissue. On the other hand, as living tissue is perfused with blood, it is reasonable, at least to the first approximation, to assume that whole blood (including water, inorganic ions, dissolved gases, organic mole cules, protein macromolecules, and cells) will sufficiently close represent the cellular/liquid structure of biological tissue.

The viscosity of blood is usually not constant and var ies between 0.003 and $0.050 \mathrm{~Pa} \cdot \mathrm{s} .^{15}$ The most intense vibration of the gaseous bubble takes place in the liquid with the lowest viscosity and as the present work is aimed at the determination of the worst casei.e., the most vigorous oscillation of the bubble - the viscosity of blood was set to be constant and equal to $0.003 \mathrm{~Pa} \cdot \mathrm{s}$. This value is also consistent with the published data on the viscosity of blood in the frequency range considered. ${ }^{16}$

\section{CALCULATION OF THE AMPLITUDE OF DISPLACEMENT OF THE VIBRATING BUBBLE WALL}

\section{A. Continuous excitation}

If an oscillating pressure $p(t)$ of amplitude $P_{A}$ and irequency $f_{A}=\omega_{A} / 2 \pi$ is applied to the system, the bubble will be set into forced radial oscillation and, under the assumptions described above, the motion of the bubble wall will be governed by the following second-order nonlinear differential equation written in spherical coordinates ${ }^{5}$ :

$\rho_{1} R \frac{d^{2} R}{d t^{2}}+\frac{3}{2} \rho_{1}\left(\frac{d R}{d t}\right)^{2}=P_{1}\left(\frac{R_{0}}{R}\right)^{3 /}-P_{0}-\frac{2 \sigma}{R}-\frac{4 \eta_{1}}{R} \frac{d R}{d t}-p(t)$,

where $P_{1}=2 \sigma / R_{0}+P_{0}$ is the pressure inside the bubble and $P_{0}$ is the hydrostatic pressure $\left(=10^{5} \mathrm{~Pa}\right) . R$ is the instantaneous radius and $R_{0}$ the equilibrium radius of the bubble.

The amplitude of bubble pulsation was obtained from the solution of Eq. (1). The equation was solved by means of numerical calculations performed on an IBM $370 / 165$ computer. The program ${ }^{17}$ permitted variation of parameters such as the intensity, the frequency, and the duty cycle of the driving sound pressure, as well as the bubble radius.

Solutions for the initial conditions $R(t=0)=R_{0}$ and $d R / d t=\dot{R}(t=0)=0$ were obtained for both steady-state (cw) and transient forced oscillations, and were aimed at modeling a bubble immersed in blood at $37^{\circ} \mathrm{C}\left(\rho_{1}\right.$ $=1056 \mathrm{~kg} / \mathrm{m}^{3}, \sigma=0.06 \mathrm{~N} / \mathrm{m}, \eta_{l}=0.003 \mathrm{~Pa} \cdot \mathrm{s}^{18}$

A representative example of the steady-state solution of Eq. (1) is shown in Fig. 2. The curve labeled " $P$ " is the driving sound pressure of the form $p(t)$ $=P_{A} \sin \omega_{A} t$; the curve labeled $* R$ is the resulting resonant bubble oscillation radius-time curve. Similar curves have been plotted for the different cases considered. The results are summarized in Table I where the displacement amplitude of the bubble wall for different parameter sets of bubble radius $R_{0}$ and relative frequency $f_{A} / f_{0}$ is given. It is here appropriate to note that for the purposes of the calculations the pressure amplitudes $P_{A}$ were chosen to be of the order of 0.2 $-10^{5} \mathrm{~Pa}$ corresponding with the levels most likely to be

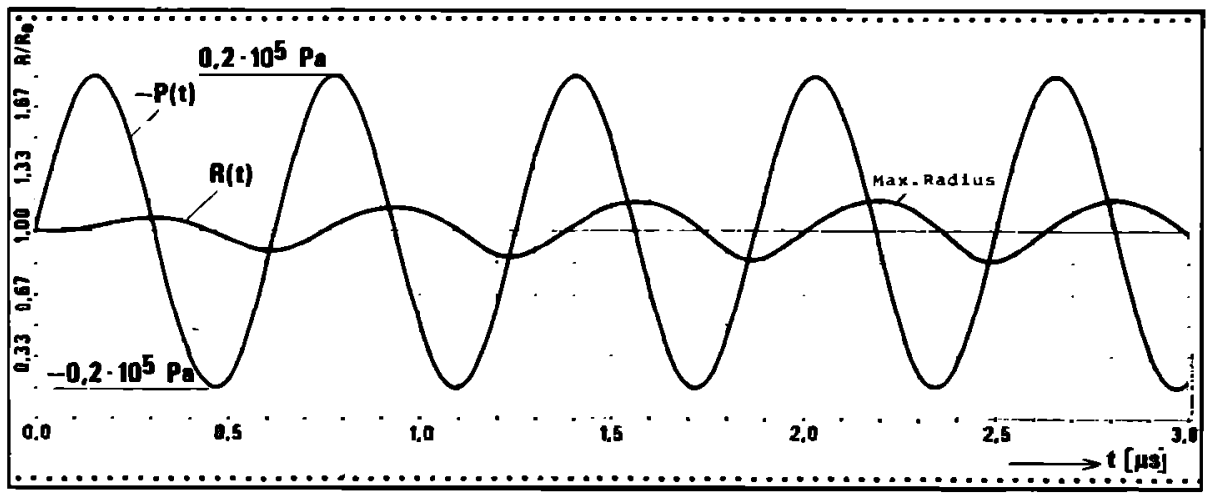

FIG. 2. Example of the steadystate solution to the bubble equation of motion. $P(t)$ is the driving ultrasound field pressure. The radiustime curve was obtained for the following parameter set: $R_{0}=2 \mu \mathrm{m}$, $f_{0}=1.6 \mathrm{MHz}$ (natural frequency), $f_{A}=1.6 \mathrm{MHz}, \eta_{t}=0.003 \mathrm{Ns} / \mathrm{m}^{2}, \sigma$ $=0.06 \mathrm{~N} / \mathrm{m}$, and $\rho_{1}=1056 \mathrm{~kg} / \mathrm{m}^{3}$. Driving pressure amplitude $P_{A}=0.2$ - $10^{5} \mathrm{~Pa}$. 
TABLE I. Calculated peak values for the displacement amplitude $\xi\left(10^{-6} \mathrm{~m}\right)$ of the vibrating bubble for different radii, frequencies, and acoustic pressure amplitudes of $P_{A}=0.2 \cdot 10^{5}$ $\mathrm{Pa}$.

\begin{tabular}{|c|c|c|c|c|c|c|}
\hline$R_{0}$ & & Dri & ag fre & ency 1 & $\mathrm{~Hz})$ & \\
\hline [Eq. (2)] & 0.86 & 1 & 1.6 & 2 & 3.6 & 4 \\
\hline$\underset{3.6 \mathrm{MHz}}{1 \mathrm{~m}}$ & 0.03 & 0.05 & 0.06 & 0.07 & 0.1 & 0.06 \\
\hline $\begin{array}{l}2 \mu \mathrm{m} \\
\quad 1.6 \mathrm{MHz}\end{array}$ & 0.11 & 0.18 & 0.3 & 0.2 & 0.07 & 0.06 \\
\hline $\begin{array}{l}3.5 \mu \mathrm{m} \\
\quad 0.86 \mathrm{MHz}\end{array}$ & 0.8 & 0.6 & 0.21 & 0.14 & 0.07 & 0.06 \\
\hline
\end{tabular}

expected at the output of medical diagnostic equipment working in the continuous wave regime. ${ }^{18-20}$

The linear resonance frequency of the bubble $f_{0}$, was calculated according to the expression ${ }^{1,5}$ :

$$
f_{0}=\frac{1}{2 \pi R_{0}\left(\rho_{l}\right)_{1 / 2}}\left[3 \gamma\left(P_{0}+\frac{2 \sigma}{R_{0}}\right)-\frac{2 \sigma}{R_{0}}-\frac{4 \eta_{1}^{2}}{\rho_{l} R_{0}^{2}}\right]^{1 / 2} .
$$

From Table I it appears that for low-pressure amplitudes in the steady-state solution, the displacement amplitude of the bubble wall reaches its maximum value for a bubble driven at its resonance frequency. This is consistent with the assumption made previously ${ }^{1}$ on the critical sizes of bubbles; that the most vigorous motion of the bubble is to be expected with bubbles of resonant size. Consequently, for quasilinear oscillations, evaluation of the worst case in terms of the maximum time-independent shear stresses acting on cell membranes in biological systems, can be limited to resonant bubbles only.

\section{B. Transient excitation}

The transient solutions were obtained by introducing the external driving pressure $p(t)$ in the following forms: (i) As an exponential decaying pulse described by the function $p(t)=P_{A} e^{-t / r}$ ( $\tau$ is the decay time constant of the pulse); (ii) as a sinusoidal tone burst; and (iii) as a waveform typical of pulses transmitted by ultrasonic diagnostic devices.

The pulse shape of the diagnostic devices was numerically synthesized by performing a Fourier analy- sis of the measured output of medical instruments ${ }^{17}$ and then applying the Fourier-Mellin theorem. This method was found to be the most suitable as it permitted possible distortion of the transmitted pulse, due, for example, to the mechanical construction of a pulse-echo transducer, to be taken into account. Details of the computer program are given in Ref. 17.

A representative example of bubble response to an applied transient pressure is shown in Fig. 3. Again the " $R$ " labeled curve depicts the radius-time curve of the bubble pulsation. " $P$ " indicates the shape of the pulse wave representing the forcing sound pressure transient. From Fig. 3 it appears that for relevant transient excitations, the bubble vibrations decay very rapidly. Thus on the basis of the above solutions to the equation of vibratory motion of the bubble, it can be concluded that for both steady-state and transient excitations, oscillating bubbles exhibit vibrations of significant amplitude. It should be noted, that for the purposes of the calculations, the pressure amplitudes have deliberately been chosen to correspond with the levels most likely to be expected at the output of medical diagnostic equipment, i.e., continuous wave regime: $I=10 \mathrm{~mW} / \mathrm{cm}^{2}$ (Refs. 17,18 ) or $P_{A}=0.2$ $\cdot 10^{5} \mathrm{~Pa}$; pulsed regime: up to $20 \cdot 10^{5} \mathrm{~Pa}$ (Ref. 17).

\section{ESTIMATION OF THE VELOCITY GRADIENT}

Determination of the velocity gradient $G$ requires in formation on the streaming velocity $U$ in the vicinity of the vibrating bubble. Qualitative insight into the physical situation can be gained by considering a gas bubble at the membrane surface which is set into vi bration in the manner shown schematically in Fig. 4.

As the bubble alternatively contracts and expands it transfers energy of vibrations to the membrane sur face and generates both oscillatory and steady (timeindependent) shear in its own vicinity. . As already mentioned, these stresses and their associated velocities can be evaluated by means of the theory of acoustic streaming near a boundary developed by Nyborg. ${ }^{21}$ His theory is the only one to date which can account for the acoustic streaming near a solid boundary and is also valid in the case of a moving boundary. ${ }^{22.23}$

Nyborg derived theoretical expressions for the acoustic streaming from the basic equations of hydrodynam-

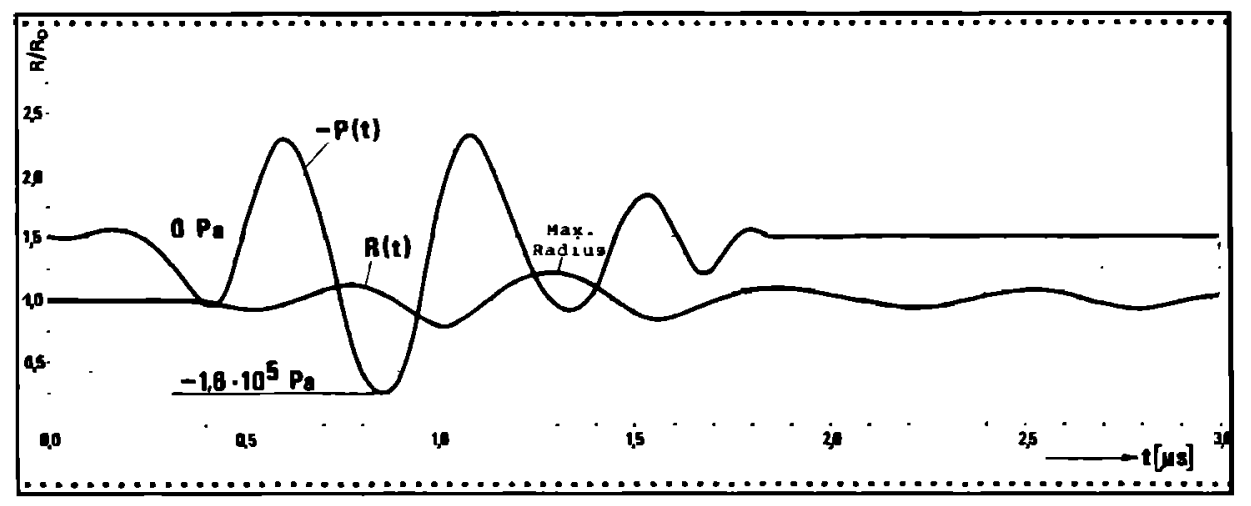

FIG. 3. An example of a trangient solution to the equation of bubble motion. The radius-time curve $R(t)$ was obtained for the following parameter set: $R_{0}=2 \mu \mathrm{m}, \eta_{t}=0.003$ $\mathrm{Pa} \cdot \mathrm{s}, \sigma=0.06 \mathrm{~N} / \mathrm{m}, \rho_{t}=1056 \mathrm{~kg} / \mathrm{m}^{3}$. $P(t)$ is a computer generated approximation of the actual output of the acoustic transducer; pressure amplitude $P_{\mathrm{A}}=1.6 \cdot 10^{5} \mathrm{~Pa}$ being characteristic for transient excited pulseecho transducers. 


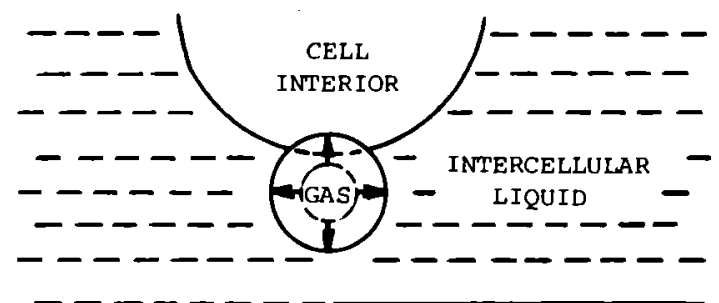

FIG. 4. A gas bubble setting up vibration in a cellular membrane. $^{3}$

ics, making use of the method of successive approximations. A more detailed description of the acoustic streaming theory is given in Refs. 17 and 24 . The theory leads to the following approximate expression for the steady streaming velocity $U$ in the boundary layer of thickness $\delta$ induced by a small hemispherical bubble of radius $R_{0}$ resting on a membrane (Fig. 5):

$$
U=Q^{2} / 4 \pi^{2} \omega_{A} R_{0}^{5}\left[1-e^{-2(1 / 0)}-3 e^{-4 / 0} \sin (z / \delta)\right],
$$

where $Q$ is the strength of the hemispherical source defined as the product of its surface area and radial first-order velocity amplitude $u_{1}, f_{A}=\omega_{A} / 2 \pi$ is the applied ultrasonic frequency and $z / \delta$ is the dimensionless distance from the membrane. The acoustic boundary layer $\delta$ can be calculated from the expression given by $\mathrm{Lamb}^{25}$ :

$$
\delta=\left(\eta_{l} / \pi \rho_{l} f_{A}\right)^{1 / 2}=\left(2 \nu / \omega_{A}\right)^{1 / 2},
$$

where $\eta_{1}$ is the coefficient of shear viscosity of the liquid, $\rho_{l}$ is its density, and $v$ is the kinematic viscosity of the liquid.

Assuming the bubble motion to be purely sinusoidal, Eq. (3) can be reduced to

$$
U=2 \pi f_{A} R_{0}\left(\xi / R_{0}\right)^{2}\left[1-e^{-2(\alpha / 0)}-3 e^{-4 / 0} \sin (z / \delta)\right],
$$

and the maximum or limiting streaming velocity can be calculated from:

$$
U_{m}=2 \pi f_{A} R_{0}\left(\xi / R_{0}\right)^{2},
$$

where $\xi$ is the peak displacement amplitude of the bubble wall determined from the nonlinear equation of bubble motion [Eq. (1)].

The normalized streaming velocity gradient $G=\partial U /$ $\partial z$ calculated from Eq. (5), is shown in Fig. 6 as a function of the distance $z / \delta$. It can be seen that $G$ changes rapidly in the vicinity of the membrane $(z=0)$. This means that a considerable shear stress $S=\eta_{1} G$ exists very close to the membrane and is almost insignificant for $z / \delta>4$.

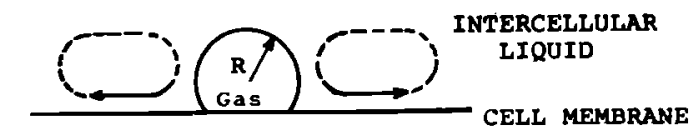

- - - - - CELL INTERIOR - - - - -

- - - - - - - - - - -

$-------------$

FIG. 5. Acoustic atreaming flow pattern induced by a vibrating bubble lying on a cell membrane. The dashed curve suggests the course of the recirculating flow. ${ }^{21}$
TABLE II. Calculated acoustic boundary layer thickness in blood [Eq. (4)].

\begin{tabular}{cc}
\hline $\begin{array}{c}\text { Frequency } \\
(\mathrm{MHz})\end{array}$ & $\begin{array}{c}\text { Acoustlc boundary layer } \\
\text { thickness }\left(10^{-6} \mathrm{~m}\right)\end{array}$ \\
\hline 0.86 & 1.02 \\
1 & 0.95 \\
1.6 & 0.75 \\
2 & 0.67 \\
3.6 & 0.50 \\
4 & 0.47 \\
\hline \hline
\end{tabular}

A calculation of $S$ for $z=0$ leads to the expression:

$$
S=\eta_{l}\left(U_{m} / \delta\right) \text {. }
$$

The acoustic boundary layer thickness in blood was calculated from Eq. (4) for the frequencies considered and is given in Table II. The values of $\rho_{1}$ and $\eta_{1}$ were $1056 \mathrm{~kg} / \mathrm{m}^{3}$ and $0.003 \mathrm{~Pa} \cdot \mathrm{s}$, respectively. ${ }^{16}$ The results from Table II were then used to calculate the stress $S$ exerted on the membrane surface.

Substituting $U_{m}$ from Eq. (6) in Eq. (7) yields:

$$
S=\left(\eta_{\mathrm{J}} / \delta\right) 2 \pi f_{\mathrm{A}} R_{0}\left(\xi / R_{0}\right)^{2} \text {. }
$$

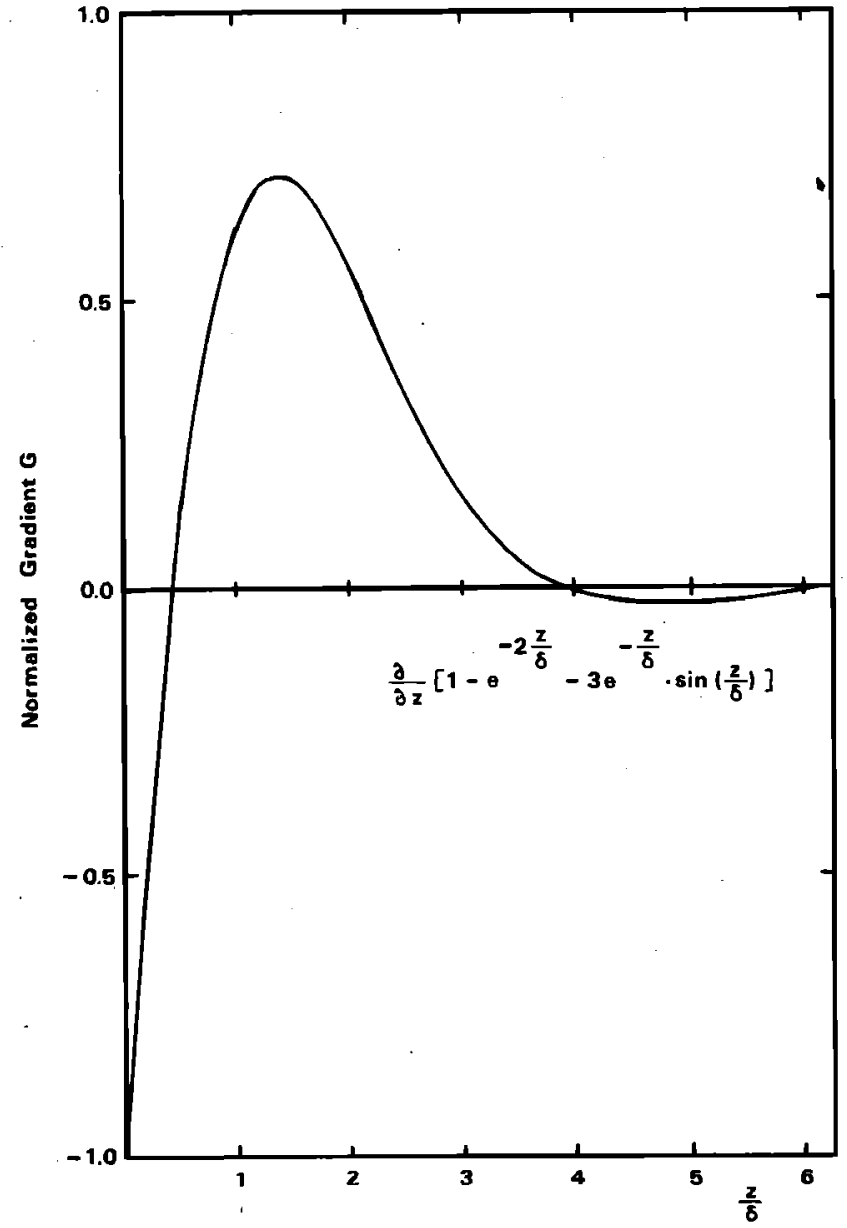

FIG. 6. Calculated, normalized streaming velocity gradient generated by membrane/bubble vibrations as a function of a distance $z / \delta$. 
The above expression can be used for the evaluation of the steady-state (hydrodynamic) shear stresses generated in the vicinity of a vibrating resonant bubble.

In most cases in the literature, rather than the values of the shear stresses that results in bioeffects being quoted, their associated velocity gradients are to be found. The velocity gradients calculated for resonant bubbles with $R_{0}=1,2$, and $3.5 \mu \mathrm{m}$ exposed to continuous sound pressure excitation are given in Table III for the value of the driving pressure amplitude which is representative of the output levels of diagnostic devices $\left(0.2 \cdot 10^{5} \mathrm{~Pa}\right)$. For the purpose of comparison, the results of the calculations for nonresonance fre quencies are also included.

The displacement amplitudes of the bubble surface $\xi$ were taken from Table $I$. The calculated velocity gradients are also compared in Table III, (last column) with critical threshold gradients for bioeffects reported by Leverett, ${ }^{26}$ Nevaril, ${ }^{27}$ Rooney, ${ }^{28}$ and Williams. ${ }^{29}$

Comparison of the theoretical gradients and the experimental critical gradients indicate that resonant bubbles introduce time-independent stresses which may lead to changes in biological structure even at the very low acoustic output levels within or very close to the range of those currently employed in medical diagnostics. The significance of this comparison is of course dependent on the validity of the assumptions of the theory used. In the next section the procedure outlined above for calculating the velocity gradients is discussed in the light of the limitations of the acoustic streaming theory employed.

\section{LIMITATIONS OF THE ACOUSTIC STREAMING THEORY}

In deriving the theory of acoustic streaming near a boundary, ${ }^{17,24}$ a number of assumptions have been made:

(i) the pulse duration of the applied ultrasound must be much longer than the period of the applied frequency;

(ii) the resulting expression for time-independent velocity applies only to minor amplitude variations of

TABLE III. Predicted velocity gradlents (1/s) associated with the vihrating resonant bubbles, $P_{A}=0.2 \cdot 10^{5} \mathrm{~Pa}$.

\begin{tabular}{|c|c|c|c|c|}
\hline $\begin{array}{l}R_{0} / f_{0} \\
{[\mathrm{Eq} .(2)]}\end{array}$ & $\begin{array}{l}\text { Driving } \\
0.86\end{array}$ & $\begin{array}{c}\text { frequency } \\
1.6\end{array}$ & $\begin{array}{r}(\mathrm{MHz}) \\
3.6\end{array}$ & $\begin{array}{c}\text { Critical } \\
\text { gradients } \\
(1 / \mathrm{s})\end{array}$ \\
\hline $\begin{array}{l}1 \mu \mathrm{m} \\
3.6 \mathrm{MHz}\end{array}$ & $4.7 \cdot 10^{3}$ & $4.8 \cdot 10^{4}$ & $4.5 \cdot 10^{5}$ & $\sim 5 \cdot 10^{4 \mathrm{a}}$ \\
\hline $\begin{array}{l}2 \mu \mathrm{m} \\
1.6 \mathrm{MHz}\end{array}$ & $3.2 \cdot 10^{4}$ & $6.0 \cdot 10^{5}$ & $1.1 \cdot 10^{5}$ & $\sim 1.5 \cdot 10^{5 \mathrm{~b}}$ \\
\hline $\begin{array}{l}3.5 \mu \mathrm{m} \\
0.86 \mathrm{MHz}\end{array}$ & $9.7 \cdot 10^{5}$ & $1.7 \cdot 10^{5}$ & $6.3 \cdot 10^{4}$ & $\sim 10^{6 \mathrm{c}}$ \\
\hline
\end{tabular}

${ }^{a}$ Hemolysis of human erythrocytes (Refs. 26 and 27).

'Membrane disruption (hemolysis) (Refs. 28 and 29).

c Hemolysis of buman erythrocytes, exposure time $10 \mu \mathrm{s}$ (Ref. 26). the acoustic pressure, as the derivation is based on perturbation theory;

(iii) the radius of the pulsating bubble must be much greater than the thickness of the acoustic boundary layer (near boundary streaming); and

(iv) it is assumed that the liquid is Newtonian, i.e., its viscosity is constant.

These assumptions will be discussed individually below.

\section{A. Pulse duration}

Acoustic streaming theory describes the steady state circulatory flow set up by sound waves in a fluid. Shear stresses and velocity gradients associated with this flow can be evaluated only when the expression for the second-order velocity $U$ is known [Eq. (5)]. The derivation of $U$ is based on time averaging over a large number of cycles. This would suggest that the theory is valid for a single exposure to pulses contain ing-say-ten periods. However, the experimental results of the visual observation of the acoustic stream ing ${ }^{17}$ indicate that streaming may be established under ultrasonic irradiation with repetitive pulses containing less than five periods. Such pulses, in the megahertz frequency range, are typical of those encountered at the output of diagnostic pulse-echo equipment.

As far as the present authors are aware, no acoustic streaming theory, fully adequate for the case of very short, repetitive pulses exists. Therefore, for pulses which contain a small number of periods, the theory should be applied with caution, since it may not necessarily yield a correct value for the velocity gradient.

\section{B. Minor pressure amplitudes}

All the fundamental expressions for the acoustic streaming theory have been derived using the general Rayleigh perturbation approach and thus require that the displacement amplitude of the bubble wall $\xi$ is much smaller than the bubble equilibrium radius $R_{0}(\xi /$ $\left.R_{0} \ll 1\right)$ and that the bubble wall motion is nearly sinusoidal. Consequently, in the range where the condition $\xi / R_{0} \ll 1$ is no longer fulfilled, i.e., for higher pressure amplitudes, the theory can only be used to obtain a qualitative indication; with an increase in excitation (pressure) amplitude, the velocity gradient $G$ can also be expected to increase. However, it is also worthwhile to note that the radius-time curve of Fig. 3, corresponding to transient excitation, seemed to remain quasisinusoidal even when the pressure amplitude of the driving signal was fairly high $\left(1.6 \cdot 10^{5} \mathrm{~Pa}\right)$. This may indicate that the acoustic streaming theory may, if careful, be applied at moderately high pulse amplitudes.

\section{Near boundary streaming approximations}

The near boundary conditions require ${ }^{17}$ that the bubble radius $R_{0}$ is large compared to the acoustic boundary layer thickness $\delta$ given by Eq. $(4),\left(R_{0} / \delta \gg 1\right)$. The 
$R_{0} / \delta$ ratios in blood have been calculated for frequencies of 1,2 , and $4 \mathrm{MHz}$, and bubble radii of 1,2 , and $3.5 \mu \mathrm{m}$, yielding the results listed in Table IV. From the results in the table it appears that the condition $R / \delta \gg 1$ is hardly fulfilled, and the consequences of this are worth more detailed discussion.

Nyborg derived his expression for the acoustic streaming velocity $U$ [Eq. (5)], under the assumption that the bubble lying on a membrane surface had a hemispherical shape (Fig. 5). However, when the acoustic boundary layer thickness $\delta$ and the radius of the bubble $R_{0}$ are of the same order of magnitude, the surface tension will tend to maintain the spherical shape of the bubble. Although the situation here is not exactly that of a free spherical bubble surrounded by an indefinitely extended liquid, as the membrane is in the vicinity (Fig. 5), it is reasonable to expect that the assumption of an hemispherical shape may lead to an overestimation of the surface velocity amplitude.

\section{Viscosity}

The acoustic streaming theory is developed using the assumption that the liquid considered is a Newtonian liquid, such as water. For the purposes of calculating the displacement amplitude of the bubble wall, it was assumed that the blood viscosity was constant and the lowest measured value of $0.003 \mathrm{~Pa} \cdot \mathrm{s}$ was chosen. ${ }^{16}$ However, as was mentioned in Sec. I, blood can exhibit non-Newtonian properties and thus its viscosity can change. In order to estimate the influence of a possible increase in the viscosity on the velocity gradients calculated (Table $\Pi 1$ ), further computer cal culations were performed in the frequency range considered, namely 1-4 M Hz. These calculations showed that a threefold increase in blood viscosity - to 0.01 $\mathrm{Pa} \cdot \mathrm{s}$-results in an approximate halving of the displacement amplitude of the bubble wall. This would lead to a decrease in the streaming velocity of a factor of four and would reduce associated viscous stresses by a factor of $4 / 3$ [Eq. (7)].

If all the above considerations are taken into account, it would appear that the velocity gradients calculated according to the theory given by $\mathrm{Nyborg}^{24}$ and listed in Table III, are an order of magnitude too high. However, it should also be noted, that even the reduced velocity gradients may lead to biological effects (cf. Table III).

\section{TIME INDEPENDENT VERSUS OSCILLATORY STRESSES}

The calculations in Secs. I-III are valid for continuous waves for single exposures which are much long-

TABLE IV. The $\boldsymbol{R}_{0} / \delta$ ratios in blood for frequencies of 1,2 , and $4 \mathrm{MHz}$.

\begin{tabular}{cccc}
\hline \hline Frequency $(\mathrm{MHz})$ & $R_{0}=1 \mu \mathrm{m}$ & $R_{0}=2 \mu \mathrm{m}$ & $R_{0}=3.5 \mu \mathrm{m}$ \\
\hline 1 & 1.05 & 2.10 & 3.68 \\
2 & 1.49 & 2.98 & 5.22 \\
4 & 2.13 & 4.26 & 7.44 \\
\hline \hline
\end{tabular}

er than the forcing frequency period (see Sec. IV). They give information on the level of the dc stresses, i.e., the stresses that are independent of time. There does appear to be some evidence for believing that the hydrodynamic shear stress threshold is time dependent. Thus Leverett et al. ${ }^{26}$ reported that the hemolysis of human erythrocytes required shear stresses of the order of magnitude of $150 \mathrm{~N} / \mathrm{m}^{2}\left(G \simeq 5 \cdot 10^{4} 1 / \mathrm{s}\right)$ during an irradiation time of $100 \mathrm{~s}$, while stresses of the order of $4000 \mathrm{~N} / \mathrm{m}^{2}\left(G \cong 1.3 \cdot 10^{6} 1 / \mathrm{s}\right)$ were necessary during an exposure time of $10 \mu \mathrm{s}$. In view of the results it is natural to inquire whether oscillatory or first-order stresses also play a role in the interaction between the ultrasound wave and biological tissue.

The first-order (oscillatory) stress can be esti mated on the basis of Lamb's results for fluid motion near a vibrating object. ${ }^{25}$ According to Lamb, the oscillatory stress in the boundary layer $\delta$, near the surface of a vibrating bubble is given by

$$
S_{1}=\eta_{1}\left(\omega_{A} \xi / \delta\right) \text {, }
$$

where $\eta_{1}$ is the viscosity of the liquid, $f_{A}=\omega_{A} / 2 \pi$ is the ultrasonic wave frequency, $\xi$ is the displacement amplitude of the bubble wall, and $\delta$ is the acoustic boundary layer thickness given by Eq. (4).

The second-order (steady-state) stresses, as shown in Sec. III, can be estimated from the acoustic streaming theory and are given by

$$
S_{2}=\eta_{1}\left(\omega_{A} \xi^{2} / \delta R_{0}\right) \cong S_{1}\left(\xi / R_{0}\right) \text {. }
$$

For the assumed values of $f_{A}=3.6 \mathrm{MHz}$, a resonant bubble radius $R_{0}=1 \mu \mathrm{m}$, a pulsation amplitude $\xi$ corresponding to the relatively low acoustic pressure of $0.2 \cdot 10^{5} \mathrm{~Pa}$ (Table I), $\delta=0.5 \mu \mathrm{m}$ (Table II), and $\eta_{i}$ $=\eta_{\text {blood }}=0.003 \mathrm{~Pa} \cdot \mathrm{s},{ }^{16}$ the steady -state stress be comes: $S_{2} \simeq 1.3 \cdot 10^{3} \mathrm{~Pa}$, while the oscillatory stress $S_{1}$ is above $1.3 \cdot 10^{4} \mathrm{~Pa}$. It can be seen that the oscillatory stresses are ten times greater than the steady state stresses, while the duration of the oscillatory stress is of the order of half of a sonic period, which for the assumed $f_{A}=3.6 \mathrm{MHz}$, corresponds to 0.138 $\mu s$.

The only data reported on the influence of such short duration stresses on biological material is that of Hamrick and Cleary ${ }^{30}$ concerning an investigation on tobacco mosaic virus. They reported that the breakage of tobacco virus particles required a velocity gradient of $4 \cdot 10^{7} \mathrm{~s}^{-1}$ of duration $0.1 \mu \mathrm{s}$. Assuming that the resulting stress could be calculated as the product of a shear viscosity $\eta_{l}$ and a velocity gradient $G$ it would correspond in a biological medium to a stress of 12 $-10^{4} \mathrm{~Pa}$. This stress is about nine times greater than the value of $S_{1}\left(1.3 \cdot 10^{4} \mathrm{~Pa}\right)$ calculated above and this seems to suggest that oscillatory stresses may be excluded as a factor contributing to damage.

\section{CONCLUSION}

The steady shear stresses in the vicinity of microbubbles irradiated with ultrasonic waves have been calculated for both continuous wave and transient ir radiations and the limitations of the calculation model 
have been assessed. Also oscillatory stresses have been estimated on the basis of the theory. The values of the shear stresses caused by continuous exposure to ultrasound were found to lie within the range in which biological effects have been reported. It is not clear for the time being whether pulse-echo diagnostic instruments give rise to sufficiently high stresses to cause damage in mammalian tissue. However, there does appear to be some evidence that thresholds for biological effects are dependent mainly on the temporal peak intensity ${ }^{31}$ while only a modest effect was found caused by the pulse repetition frequency thus changing the average intensity. ${ }^{31}$ A variation of bioeffects with repetition frequency when the pressure amplitude is kept constant suggests that acoustic streaming theory may not be entirely adequate to explain the effect observed. It emphasizes the need for more extensive ex periments on biological effects, with carefully controlled exposure parameters, and for better fundamental data for theoretical calculations.

\section{ACKNOWLEDGMENTS}

One of the authors, Peter A. Lewin, is indebted to Professor W. L. Nyborg and Dr. D. L. Miller, Physics Department, University of Vermont, Burlington, for the valuable suggestions and assistance, that they so freely have given during his stay at their department. Financial support of the Danish Research Council for Technical Sciences, which allowed a prolonged stay for P. A. Lewin at the University of Vermont, is gratefully acknowledged.

${ }^{1} \mathrm{P}$. A. Lewin and L. Bjorno, "Acoustic pressure amplitude thresholds for rectified diffusion in gaseous microbubbles in biological tissue," J. Acoust. Soc. Am. 69, 864-852 (1981). ${ }^{2} \mathrm{~J}$. A. Rooney, "Shear as a mechanism for sonically induced biological effects," J. Acoust. Soc. Am. 52, 1718-1724 (1972).

${ }^{3}$ W. L. Nyborg, "Mechanism for nonthermal effects of sounds," J. Acoust. Soc. Am. 44, 1302-1308 (1968).

${ }^{4}$ Lord Rayleigh, "On the pressure developed in a liquid during the collapse of a spherical cavity," Philos. Mag. 34, 94-98 (1917).

${ }^{5}$ B. E. Noltingk and E. A. Neppiras, "Cavitation produced by ultrasonics," Proc. Phys. Soc. London, B 63, 674-685 (1950).

${ }^{6} \mathrm{M}$. Plesset and T. Mitchell, "On the stability of the spherical shape of a vapor cavity in a liquid," Appl. Math. 13, 419-430 (1956).

${ }^{7}$ M. Plesset, "Bubble dynamics," in Cavitation in Real Liquids, edited by R. Davies (Elsevier, Amsterdam, 1964).

${ }^{8} \mathrm{~A}$. Prosperetti. "Nonlinear oscillations of gas bubbles in liquids: Steady state solutions," J. Acoust. Soc. Am. 56, 878-885 (1974).

${ }^{9} \mathrm{~W}$. Lauterborn, "Numerical investigations of nonlinear oscillations of gas bubbles in liquid," J. Acoust. Soc. Am. 59, 283-293 (1976).

${ }^{10} \mathrm{~A}$. Prosperetti, "Thermal effects and damping mechanisms in the forced radial oscillations of gas bubbles in liquids," J. Acoust. Soc. Am. 61, 17-27 (1977).

${ }^{11} M$. Strasberg, "The pulsation frequency of nonspherical gas bubbles in liquids," J. Acoust. Soc. Am. 25, 536-537 (1953).

${ }^{12} \mathrm{D}$. Y. Hsieh, "Variation methods and dynamics on non-spherical bubbles and liquid drops," in Finate-Amplitude Wave Effects in Fluid, Proceedings of the 1973 Symposium, edited by L. Bjorno, (IPC, Surrey, England, 1974), pp. 220-227.

${ }^{13} \mathrm{C}$. Devin, "Survey of thermal, radiation and viscous damping of pulsating air bubbles in water," J. Acoust. Soc. Am. $31,1654-1667$ (1959).

${ }^{14}$ R. B. Chapman and M. S. Plesset, "Thermal effects in the free oscillations of gas bubbles," Report NRD, No. AD 708454.

${ }^{15}$ E. W. Merril, E. R. Gilliland, G. Cokelet, H. Shin, A. Britten, and R. E. Wells, Jr., "Rheology of human blood, near and at zero flow. Effects of temperature and hematocrit level," Biophys. J. 3, 199-212 (1963).

${ }^{16} \mathrm{R}$. Y. Nishi, "The scattering and absorption of sound waves by a gas bubble in viscous liquid," Acustica 39, 65-74 (1975).

${ }^{17}$ P. A. Lewin, "Ultrasound induced damage of biological tissue," Ph. D. thesis, Technical University of Denmark (1978).

${ }^{18}$ P. L. Carson, P. R. Fischella, and T. V. Oughton, "Ultrasonic power and intensities produced by diagnostic ultrasound equipment," Ultrasound Med. Biol. 3, 341-350 (1978).

${ }^{19} \mathrm{C}$. R. Hill, "Acoustic intensity measurements on ultrasonic diagnostic devices," in Untrasonographic Medica, edited by J. Bock and K. Ossoinig (Verlag der Wiener Medizinischen Akademie, Vienna, 1971), pp. 21-27.

${ }^{20}$ M. J. Farmery and T. A. Whittingham, "A portable radiation-force balance for use with diagnostic ultrasound equipment," Ultrasound Med. Biol. 3, 373-379 (1978).

${ }^{21} \mathrm{~W}$. L. Nyborg, "Acoustic streaming near a boundary," J. Acoust. Soc. Am. 30, 329-339, (1958).

${ }^{22} \mathrm{M}$. S. Longuet-Higgins, "Mass transport in water waves," Phil. Trans, R. Soc. London Ser. A245, 535-581 (1953).

${ }^{23} \mathrm{M}$. S. Longuet-Higgins, "Mass transport in the boundary layer at a free oscillations surface," J. Fluid Mech. 8, 293-306 (1960).

${ }^{24}$ W. L. Nyborg, Acoustic Streaming, Physical Acoustics Vol. $I$, Part B, edited by W. P. Mason (Academic, New York, 1965).

${ }^{25} \mathrm{H}$. Lamb, Hydrodynamics (Dover, New York, 1945), 6th ed.

${ }^{26}$ L. B. Leverett, J. D. Hellums, C. P. Alfrey, and E. C. Lynch, "Red blood cell damage by shear stresses," Biophys. J. 12, 257-273 (1972).

${ }^{27}$ C. G. Nevaril, E. C. Lynch, C. P. Alfrey, and J. D. Hellums, "Erythrocyte damage and destruction induced by shear stress," J. Lab. Clin. Med. 71, 784-790 (1968).

${ }^{28} \mathrm{~J}$. A. Rooney, "Hemolysis near an ultrasonically pulsating gas bubble," Science 169, 869-871 (1970).

${ }^{29}$ A. R. Williams, D. E. Hughes, and W. L. Nyborg, "Hemolysis near a transversely oscillating wire," Science 169 , 871-873 (1970).

${ }^{30} \mathrm{Ph}$. E. Hamrick and S. F. Cleary, "Breakage of tobacco mosaic virus by acoustic transients - a hydrodynamic model," J. Acoust. Soc. Am. 45, 1-6 (1969).

${ }^{31}$ S. 2. Child, E. Carstensen, and S. K. Lam, "Effects of ultrasound on Drosophila. III Exposure of larvae to low-temporal-average intensity, pulsed irradiation," Ultrasound Med. Biol. 7, 163-173 (1981). 